\title{
Immobilization of industrial waste in cement-bentonite clay matrix
}

\author{
I B PLECAS* and S DIMOVIC \\ VINCA Institute of Nuclear Sciences, P. O. Box 522, 11001 Belgrade, Serbia and Montenegro
}

MS received 22 August 2003; revised 16 February 2004

\begin{abstract}
Results of a series of experimental tests performed to determine the influence of matrix characteristics on the leaching mechanism of copper aluminum oxychloride immobilized into cement matrices are presented. The objective of this work was to investigate the leaching mechanism of copper as a constituent of copper aluminum oxychloride ('CAOX'). Transport phenomena involved in the leaching of a waste material from a composite matrix into surrounding water were investigated using three methods based on theoretical equations: (i) diffusion equation derived for a plane source model, (ii) rate equation for diffusion coupled with a first-order reaction and (iii) the leaching data were also analysed by an empirical method employing a polynomial equation. These three methods are compared with respect to their applicability to the leaching data.
\end{abstract}

Keywords. Immobilization; leaching; waste; cement; bentonite; diffusion.

\section{Introduction}

Immobilization keeps gaining in stature as a key technology for remedying hazardous waste. The technique consists of entrapping the waste within a solid matrix having high structural integrity and minimizing the risk of escape by leaching. Wastes from a wide range of industrial sources have been solidified. Among these are chemical, metal, textile, wood processing and petroleum refining industries. The waste may consist of liquids, sludge, slurries, or contaminated soil and sediments.

Solidification techniques are usually categorized by the type of solidifying agents used. Chemical fixation of toxic and hazardous waste using cement has been practiced for many years. Portland cement is the most popular solidification agent for inorganic wastes. Its high $\mathrm{pH}$ tends to keep metals in their most insoluble forms (i.e. as hydroxides and carbonates), thus minimizing subsequent leaching. Portland cement is less useful with organics, since some of them interfere with the overall setting and curing process (Hashimoto 1964; Goodbee 1969; Burns 1971).

\section{Copper aluminum oxychloride (CAOX) description}

' $\mathrm{CAOX}$ ' is a waste material produced in methanol and acetic acid industry as a product of solvent 'COSORB' (cuprous aluminum tetrachloride). The most common compound which will react with the COSORB solvent is

*Author for correspondence water. Water reacts irreversibly with the COSORB solvent to precipitate cuprous chloride, liberate hydrogen chloride, and produce copper aluminum oxychloride. This reaction takes place in 2 steps as follows:

$$
\begin{aligned}
2 \mathrm{CuAlCl}_{4} \cdot \mathrm{C}_{7} \mathrm{H}_{8}+\mathrm{H}_{2} \mathrm{O} \rightarrow & \mathrm{HCl}+\mathrm{CuCl} \\
+ & \mathrm{CuAlCl}{ }_{4} \cdot \mathrm{Al}(\mathrm{OH}) \mathrm{Cl}_{2} \cdot \mathrm{C}_{7} \mathrm{H}_{8}, \\
\mathrm{CuAlCl}_{4} \cdot \mathrm{Al}(\mathrm{OH}) \mathrm{Cl}_{2} \cdot \mathrm{C}_{7} \mathrm{H}_{8} & \rightarrow \mathrm{HCl} \\
& +\mathrm{CuAlCl}{ }_{4} \cdot \mathrm{AlOCl} \cdot \mathrm{C}_{7} \mathrm{H}_{8} .
\end{aligned}
$$

The first reaction takes place immediately after introduction of water into the absorber. Part of the $\mathrm{HCl}$ formed will exit the absorber in the overhead gas. A small part of the $\mathrm{HCl}$ will be absorbed into the solvent and be coproduced with carbon monoxide.

The second reaction takes place more slowly and requires heat to drive the reaction to completion. The $\mathrm{HCl}$ produced from the second reaction will be coproduced with carbon monoxide exiting the stripper overhead. The aluminum oxychloride produced by water reaction will complex with the COSORB solvent. This new complex still retains its ability to complex carbon monoxide; however, the solubility of the aluminum oxychloride complex is less than that of the original complex. Plugging of the unit will start at higher temperature as the water contamination continues and the concentration of aluminum oxychloride complex increases in the COSORB solvent. The absorption ability of the COSORB solvent is proportional to the concentration of copper in the solvent. This paper describes initial results obtained from series of experimental tests carried out on three different formulas of cementing matrices for immobilized copper aluminum 
oxychloride. Copper was chosen as the contaminant element.

\section{Materials and mortar composition}

Grout samples have been made up of Portland cement PC-45 MPa; water; additives: super fluidal (plasticizer); bentonite clay $\left(63 \% \mathrm{SiO}_{2} ; 18 \% \mathrm{Al}_{2} \mathrm{O}_{3} ; 4 \% \mathrm{Fe}_{2} \mathrm{O}_{3} ; 2,6 \%\right.$ $\mathrm{MgO}$ and $3,3 \% \mathrm{CaO}$ ) and ' $\mathrm{CAOX}$ '. Composition of three grout-waste forms are shown in table 1.

\section{Experimental}

After sufficient mixing of the constituents shown in table 1 , the paste was poured into a cylindrical vessel (diameter and height, $5 \mathrm{~cm}$ ). The curing time of specimens was $28 \mathrm{~d}$. The leaching test was carried out according to the method recommended by literature (Hespe 1971). The specimen taken from a cylindrical vessel immediately before the test was immersed in the leaching vessel containing $200 \mathrm{ml}$ of tap water at $21^{\circ} \mathrm{C}$. Duration of leaching renewal period $(d)$, was 28 days. At intervals the leachant was removed and the concentration of copper measured using a PERKIN-ELMER atomic absorption spectrophotometer.

\section{Theoretical methods}

Transport phenomena involved in the leaching of waste material from a composite matrix were investigated using three methods based on theoretical equations. Three methods are compared with respect to their applicability to experimental leaching data (Hashimoto 1964; Goodbee 1969; Burns 1971; Morijama 1977; Lu 1978; Plecas et al 1985, 1990, 1991).

\subsection{Method I: Diffusion equation based on a plane source model}

In this model the fraction, $f$, leached at time, $t(d)$, is given in literature data (Hespe 1971; Morijama 1977; Lu 1978)

$$
f=\frac{\Sigma a_{n}}{A}=\frac{2 S \sqrt{D t_{n}}}{V \sqrt{\pi}}
$$

where $\Sigma a_{n}$ is the cumulative fraction leached of contaminant for each leaching period $(\mathrm{mg} \mathrm{CuI}), A_{0}$ the initial amount of contaminant in sample (mg CuI), $V$ the volume of sample $\left(\mathrm{cm}^{3}\right), S$ the exposed surface area of sample $\left(\mathrm{cm}^{2}\right)$ and $t_{n}$ the duration of leachant renewal period $(d)$.

The results may also be expressed by the cumulative fraction of contaminant. Leach test results are plotted as cumulative fraction of contaminant leached from the samples as a function of the square root of total leaching time: $f$ vs $\sqrt{ } \Sigma t_{n}$.

When this is true, a plot of $\Sigma a_{n}$ vs $\sqrt{ } \Sigma t_{n}$ is a straight line and the diffusion coefficient, $D_{\mathrm{e}}$, is expressed by

$$
D_{\mathrm{e}}=\frac{\pi}{4} m^{2} \frac{V^{2}}{S^{2}}\left(\mathrm{~cm}^{2} \mathrm{~s}^{-1}\right)
$$

where $D_{\mathrm{e}}$ is the diffusion coefficient $\left(\mathrm{cm}^{2} \mathrm{~s}^{-1}\right), m=\left(\sum a_{n} /\right.$ $\left.A_{0}\right)(1 / \sqrt{ } \Sigma t)$, slope of straight line $\left(d^{-1 / 2}\right)$.

\subsection{Method II: Rate equation for coupled diffusion and simultaneous first-order reaction}

In this model, the rate equation is

$$
\frac{\partial C}{\partial t}=D\left(\partial^{2} C / \partial X^{2}\right)+g(C)
$$

Here, a special case was considered where $g(C)$ is directly proportional to the concentration $C$, i.e. a first-order reaction. The initial and boundary conditions are,

$$
\begin{aligned}
& t=0, \alpha>x>0, C=C_{0}, \\
& t=0, x<0, C=0 \\
& t>0, x=0, C=0
\end{aligned}
$$

From this, the fraction leached from a specimen having a surface area, $S\left(\mathrm{~cm}^{2}\right)$, and volume, $V\left(\mathrm{~cm}^{3}\right)$ is

$$
\begin{aligned}
f= & (S / V) \sqrt{D / k}[(k t+1 / 2) \bullet \operatorname{erf} \sqrt{k t} \\
& +\sqrt{k t / \pi} \exp (-k t)]
\end{aligned}
$$

where $k$ is the rate constant (proportional constant) of the first-order reaction.

$$
\operatorname{erf}(u)=\text { err. function }=(2 / \sqrt{\pi}) \int_{0}^{u} \exp \left(-z^{2}\right) \mathrm{d} z
$$


Table 2. Experimental results of cumulative fraction leached, $\left(\Sigma a_{n} / A_{0}\right) \cdot 10^{4}$, of contaminant $\mathrm{Cu}$ I, for leaching period of 28 days.

\begin{tabular}{lcccccccccc}
\hline$\sum a_{n} / A_{0}$ & 2,11 & 2,82 & 3,43 & 3,88 & 4,55 & 4,65 & 5,13 & 7,21 & 8,14 & 9,06 \\
$t(d)$ & 1 & 2 & 3 & 4 & 5 & 6 & 7 & 14 & 21 & 28 \\
\hline
\end{tabular}

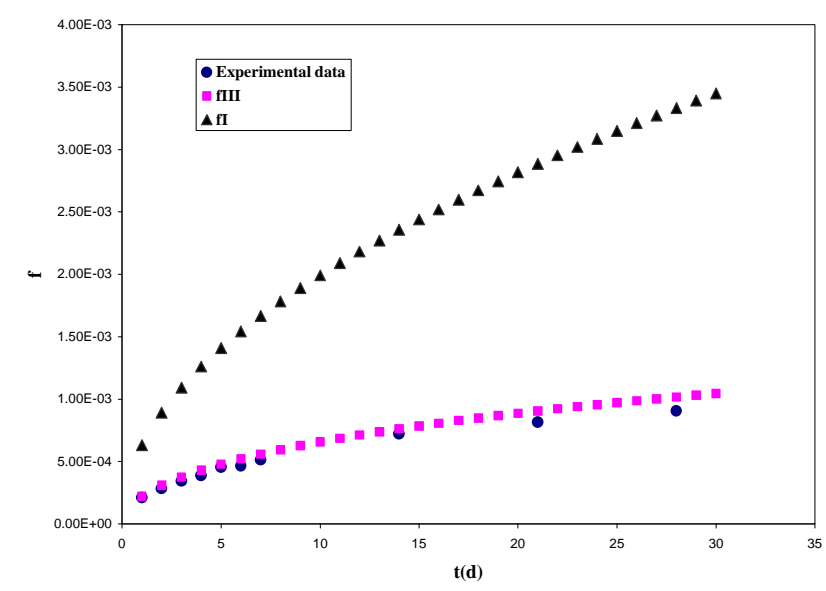

Figure 1. Plot of $f$ against $t$ for leaching of copper from cement matrix (methods I, III, and experimental data).

\subsection{Method III: Polynomial equation}

The orthogonal polynomial is one of the most useful empirical equations. Its general form is

$$
y(x)=\sum_{i=1}^{n} A_{i} \phi_{i}(x)
$$

where $A$ is the parameter to be determined, and ${ }_{i}$ a function of $x$. Here, ${ }_{i}(x)$ is taken as $t^{i / 2}$, and the leaching fraction is given by

$$
f=\sum_{i=1}^{n} A_{i} t^{i / 2}
$$

To simplify the mathematical treatment, a fifth degree polynomial of the form

$$
f=A_{0}+A_{1} t^{1 / 2}+A_{2} t+A_{3} t^{3 / 2}+A_{4} t^{2},
$$

was fitted to the leaching data.

For this type of model, extrapolation to longer term leaching is not advisable since the arbitrary constants do not necessarily have any physical significance.

\section{Results}

Table 2 presents experimental results of cumulative fraction leached, $\Sigma a_{n} / A_{0}$ of contaminant $\mathrm{Cu}$ I, for leaching pe- riod of 28 days. Experimental data shows the fraction of copper leached from cement composites as a function of the square root of leaching period. Linear relation between $f$ and $t^{1 / 2}$ is not observed throughout the tested period. From the application of method I to the leaching data, we obtained

$$
f_{\mathrm{I}}=6,310^{-4} \sqrt{t}+4,8010^{-12}
$$

The diffusion coefficients predicted by method I are

$$
D_{\mathrm{I}}=3,6010^{-9}\left(\mathrm{~cm}^{2} / \mathrm{d}\right)
$$

Method II was applied to the leaching data to obtain the unknown parameters, $D$ and $k$. From this we obtained

$$
\begin{aligned}
D_{\mathrm{II}} & =3,70 \times 10^{-9}\left(\mathrm{~cm}^{2} / \mathrm{d}\right), \\
k_{\mathrm{II}} & =3,40 \times 10^{-2}\left(\mathrm{~d}^{-1}\right) .
\end{aligned}
$$

Using the method of least squares, method III yielded

$$
\begin{aligned}
f_{\mathrm{III}}= & -4,210^{-6}+2,3010^{-4} t^{1 / 2}-5,010^{-6} t \\
& -6,3010^{-7} t^{3 / 2}+4,8010^{-8} t^{2} .
\end{aligned}
$$

Figure 1 presents plot of $f$ vs $t$ for leaching data of copper from cement matrix, for methods I and III and experimental data.

\section{Conclusions}

Method I cannot describe the whole leaching process; it is very convenient to simulate leaching over a longer period because of its simplicity. Despite the very complex numerical treatment required, the applicability of method II to the present data is only comparable to that of method I. Method III gives the best approximations during the whole period tested. Finally, the solidification technique of copper aluminum oxychloride ('CAOX') is satisfied by cement immobilization.

\section{Acknowledgements}

This work was supported by the Ministry of Science, Technologies and Development of the Republic Serbia under Contract No. 1985 (Research and Development of processes and materials for treatment of radioactive and hazardous waste and environmental hazard assessment). 


\section{References}

Burns R H 1971 Atomic Energy Rev. 9547

Goodbee H W 1969 Trans. Am. Nucl. Soc. 12450

Hashimoto I, Deshpande K B and Thomas C H 1964 JEC Fundamentals 3213

Hespe E D 1971 Atomic Energy Rev. 9195

Lu A H 1978 Health Phys. 3439
Morijama N, Dojiri S and Matsuzuru H 1977 Health Phys. 33549

Plecas I, Mihajlovic L and Kostadinovic A 1985 Radioactive Waste Management and Nuclear Fuel Cycle 6161

Plecas I, Drljaca J, Peric A, Kostadinovic A and Glodic S 1990 Radioactive Waste Management and Nuclear Fuel Cycle $\mathbf{1 4}$ 195

Plecas I, Peric A, Kostadinovic A and Drljaca J 1991 J. Radioanal. Nucl. Chem. Lett. 154121 